\title{
PHYTOL SYNTHESIS FROM GERANYLGERANIOL IN SPINACH CHLOROPLASTS
}

Jürgen Soll and Gernot Schultz

Institut für Tierernährung, Arbeitsgruppe für Phytochemie und Futtermittelkunde, Tierärztliche Hochschule, Bischofsholer Damm 15, D-3000 Hannover 1

SUMMARY: The reduction of $/ 2-{ }^{14} \mathrm{C} /$-geranylgeranylpyrophosphate to phytylpyrophosphosphate is shown for the first time in chloroplasts. The esterification of exogenous $/ 2-{ }^{4} \mathrm{C} /$-geranylgeranyl pyrophosphate wi th endogenous chlorophyllide and the stepwise reduction of the pigment bound geranylgeraniol to phytol was also proved for spinach chloroplasts for the first time.

INTRODUCTION: The two diterpenes geranylgeraniol (GG) and phytol (P) play an important role in the chloroplasts of higher plants through their function as intermediates in the synthesis of components such as chlorophyll ( $\mathrm{CHI}$ ), phylloquinone and tocopherol $(T)$. A stepwise 2 electron reduction of $\mathrm{Chl}$ a esterified with $G G\left(C h l a_{G G}\right)$ to $C h l$ a was demonstrated for different etiolated seedlings and etioplasts systems $(1-4)$. GG was shown to be the precursor of phytol in whole leaves (5). The reduction of GG or GG-pyrophosphate (GGPP) to $P$ or phytylpyrophosphate (PPP) could not yet be demonstrated in iso lated chloroplasts. This reaction however is essential for the synthesis of $\alpha$-tocopherol $(\alpha T)$ in chloroplasts (6). The enzyme which catalyses the incorpora tion of PPP in $\alpha T$ precursors is strongly specific for PPP and does not use GGPP (6). Here we report for the first time the reduction of $G G \rightarrow P$ and of $\mathrm{Chl} \mathrm{a}_{\mathrm{GG}} \rightarrow \mathrm{Chl}$ a for intact purified spinach chloroplasts.

MATERIAL AND METHODS: Radiochemiçals: $12-{ }^{14} \mathrm{C} /-$ ethylbromacetate (spec. act. 4.7 $\mathrm{mCi} / \mathrm{mmol}$ ) was purchased from Amersham Buchler (Braunschweig). GG was a gift from Dr. W. Hoffmann (BASF, Ludwigshafen). All-trans farnesylacetone was a gift from Dr. F. Weber, Hoffmann-La Roche, Basel).

Synthes is of $\angle 2=14 \mathrm{C} /$-geranylgeraniol: This synthesis is a multistep synthesis, the intermediafes were neither isolated nor purified inbetween.

a) Synthesis of $/ 2-{ }^{4} \mathrm{C} /$-triethyl phosphonoacetate (7): $0.19 \mathrm{mmol}$ triethylphosphite were heated with $0.175 \mathrm{mmol} / 2-{ }^{4} \mathrm{C} /$-ethylbromacetate $5 \mathrm{~h}$ under reflux at $115-125^{\circ} \mathrm{C}$.

b) Synthesis of $/ 2-{ }^{14} \mathrm{C} /-3,7,11,15$-tet ramethy $1-2,6,10,14$-hexadecatet raene-1acidethylester: The in a) formed intermediate was suspended in $200 \mu l$ of dimethoxyethane and $0.4 \mathrm{mmol} \mathrm{NaH} \mathrm{(50 \%} \mathrm{dispersion} \mathrm{in} \mathrm{oil)} \mathrm{were} \mathrm{added} \mathrm{at}-18^{\circ} \mathrm{C}$ over a period of $0.5 \mathrm{~h}$. The solution was stirred for another $0.75 \mathrm{~h}$, then $0.16 \mathrm{mmol}$ all-trans farnesylacetone $(6,10,14$-trimethyl-5,9,13-pentadecatri- 
ene-2-on) was added. It was heated at $60^{\circ} \mathrm{C}$ for $4.5 \mathrm{~h}$ and stirred for $15 \mathrm{~h}$ at room temperature. The solution was extracted with $E t_{2} \mathrm{O}$ and the $E t_{2} 0$-phase

c) Synthesis of $/ 2-{ }^{14} \mathrm{C} /-\mathrm{GG}$ : The intermediate ester was resolved in $500 \mu 1 \mathrm{Et}_{2} \mathrm{O}$ and $40 \mathrm{mg} \mathrm{LiAlH}_{4}$ were added at $-30^{\circ} \mathrm{C}$ over a period of $0.5 \mathrm{~h}$. The solution

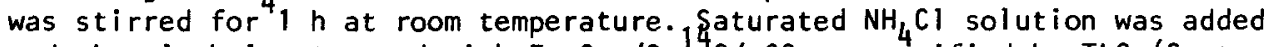
and the alcohol extracted with $\mathrm{Et}_{2} 0.12-{ }^{14} \mathrm{C} /-\mathrm{GG}$ was purified by TLC (System I) on silicagel plates. A solvent system of petroleum (b.p. $60-80^{\circ} \mathrm{C}$ ) $/ \mathrm{Et}_{2} \mathrm{O}^{1: 1}$ $(v / v)$ was used. The yield after purification on System I was $63 \%$ (spec. act. $1.2 \mathrm{mCi} / \mathrm{mmol}$ ). According to the radioscan the purity was $97 \%$. The synthesized GG is a mixture of $70 \% E$ and $30 \% Z(8,9)$.

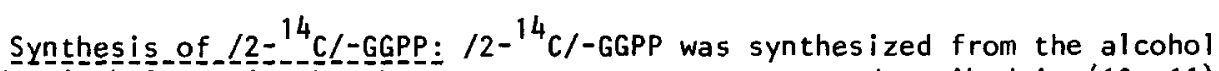
and triethylammoniumphosphate as tetraammoniumsalt as described in $(10,11)$.

Isolation_of_purífied_chloroplasts: Chloroplasts were isolated from fieldgrown spinach by standard methods $(12)$. They were further purified on percoll gradient (13). To assure free passage of ATP and $/ 2-{ }^{4} \mathrm{C} /-\mathrm{GGPP}$ through the chloroplast envelope the intact purified chloroplasts were osmotically shocked in hypotonic buffer solution (HEPES ( $N$-2-hydroxyethylpiperazine-N'-2-ethanesulfone acid) $\left.10 \mathrm{mM} \mathrm{pH} 7.6 ; 4 \mathrm{mM} \mathrm{MgCl}_{2}\right)$.

Reaction mixture: The complete reaction contained, if not otherwise defined: $10 \mathrm{mM}$ HEPES $\mathrm{pH}_{14} .6 ; 4 \mathrm{mM} \mathrm{MgCl}_{2} ; 2 \mathrm{mM} \mathrm{MnCl} ; 0.1 \mathrm{mM} \mathrm{NaF} ; 0.5 \mathrm{mM}$ ATP; $10 \mathrm{mM}$ $\mathrm{NaHCO}_{3} ; 0.5 \mathrm{mM} / 2-{ }^{14} \mathrm{C} /-\mathrm{GGPP}$; the final volume of $1 \mathrm{ml}$ contained not less than $3 \mathrm{mg}$ of chlorophyll. The chloroplast suspension was illuminated $\left(0.1 \mathrm{~J} / \mathrm{cm}^{2}\right.$ $\mathrm{sec})$ and slowly stirred at $20^{\circ} \mathrm{C}$ in the water bath.

Chromatography_of_products: Aliquots $(300 \mu l)$ were taken at different times. The reaction was stopped and the lipids extracted in a $\mathrm{MeOH} / \mathrm{CHCl}, \mathrm{mix}-$ ture according to $(14)$. For better purification Chl were converted to phaeophytins (Phae) and the terpenoid-PP were hydrolized to the corresponding alcohols in the extraction mixture by acidification with $\mathrm{HCl}$ (final conc. $1 \mathrm{~N}$ ) at $37^{\circ}$ for $0.5 \mathrm{~h}(10)$. Unlabeled $P$ was added as carrier and the products were purified on System 1 . The isoprenoids were rechromatographed on silicagel plates (impregnated with $10 \% \mathrm{AgNO}_{3}$ in EtOH / acetonitrile $9: 1(\mathrm{v} / \mathrm{v})$. A solvent system of $n$-hexan $/ \mathrm{di}$-isopropylether $/$ ethylacetate $2: 1: 1(\mathrm{v} / \mathrm{v} /$ v) was used. (System II). Phae was saponified by $0.5 \mathrm{M} \mathrm{KOH}$ in $\mathrm{MeOH} 0.5 \mathrm{~h} \mathrm{un-}$ der reflux. The reaction was carried out under $N_{2}$, pyrogallol, $G G$ and $P$ were added. The reaction mixture was extracted with $\mathrm{Et}_{2}{ }^{0}$, washed free of alkali and the terpenoid alcohols were chromatographed on System 11 . The terpenoid alcohols were visualized by spraying with $20 \%$ molybdatophosphoric acid in $\mathrm{MeOH}$ and heating at $120^{\circ} \mathrm{C}$. The radioactive areas were scraped off the plates, dissolved in $2 \mathrm{ml} \mathrm{MeOH}$ and were counted in $5 \mathrm{ml}$ scintillation mixture (Hydroluma, Baker, Groß Gerau, West Germany) using a Packard liquid scintillation counter.

RESULTS: Reduction_of_free_GGPP: When purified spinach chloroplasts were incubated in the presence of $/ 2-{ }^{14} \mathrm{C} /-\mathrm{GGPP}$ labeled phytol could be detected as product (see Fig. 1).

Reduction_of_Chl_a ${ }_{G G}$ : The synthesis of $\mathrm{Chl}$ a ${ }_{\mathrm{GG}}$ from IPP was shown in a recombined system of thylakoids and soluble chloroplast proteins for spinach (14). 


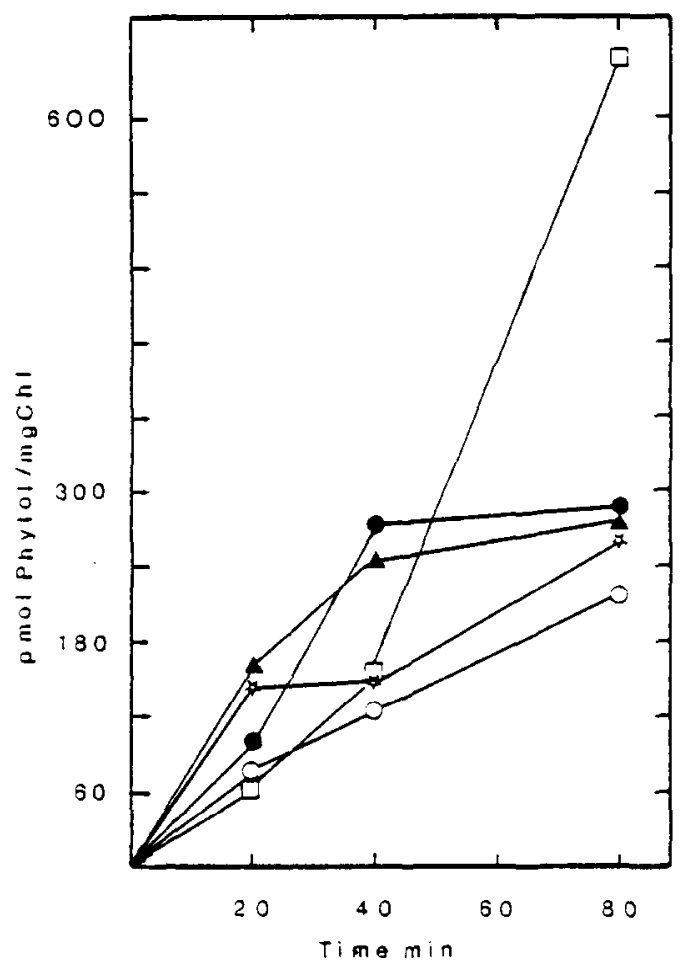

Figure 1: Time course incorporation of $/ 2-{ }^{14} \mathrm{C} / \mathrm{GGPP}$ in phytol by spinach chloroplasts. $\triangle \mathrm{NADPH}(3 \mathrm{mM}) ;-\mathrm{NADPH}(3 \mathrm{mM})+\mathrm{FADH}_{3}(0.1 \mathrm{mM})$; 0 FADH $_{2}(0.1 \mathrm{mM})+$ dithiothreitol $(2 \mathrm{mM}) ; * \mathrm{NADPH}(3 \mathrm{mM})+$ FAD $(0.1$ $\mathrm{mM})$; $\square$ RADPH $(3 \mathrm{mM})+\mathrm{FADH}_{2}(0.1 \mathrm{mM})+$ dithiothreitol (2 mM) + thioredoxin $(80 \mu \mathrm{g})$. For further details see Material and Methods.

A stepwise reduction to $\mathrm{Chl}$ a which is proved in etiolated systems could not be demonstrated for this recombinated system (personal communication of Prof. Dr. R. Douce). As shown in Fig. 2 the reduction of $\mathrm{Chl} \mathrm{a}_{\mathrm{GG}}$ can occur with good yields also in the green system. The reduction is very quick. Labeled phytol could already be detected after $5 \mathrm{~min}$ (data not shown). Exogenously NADPH effects in a higher yield in the chlorophyll bound terpenoids DHGG (dihydro-GG) and THGG (tetrahydro-GG) (compare Fig. $2 a$ and $b$ ). This is in good agreement with the results in ref. (3). The determination of DHGG and THGG was done by their characteristics on thinlayers chromatograms (compare 1, 3 , 15).

DISCUSSION: The results show for the first time that the last step in $P$ biosynthesis is also performed in the chloroplast. Until now only indirect evidence was given for this reaction by the incorporation of various precur- 

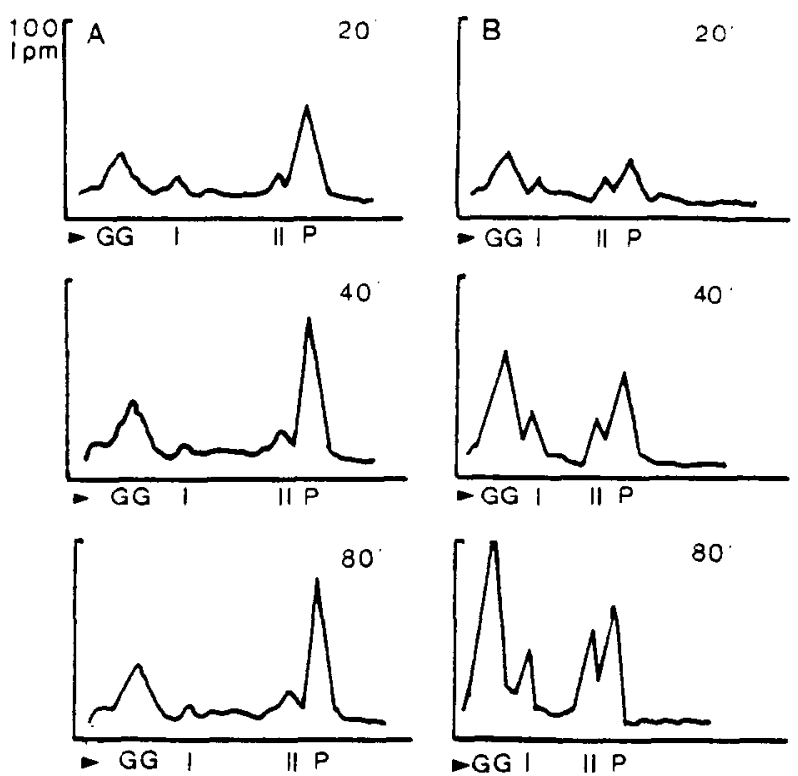

Figure 2: Radioscan of the time course incorporation (20, 40,80 min) of $12-{ }^{14} \mathrm{C} /-\mathrm{GGPP}$ in $\mathrm{Chl}$ a by purified spinach chloroplasts. Chloroplasts were incubated as described in Material and Methods. The radioscan shows the rechromatography of the terpenoids after saponification on System 11 . Incubation mixture plus: A) $\mathrm{FADH}_{2}(0.1 \mathrm{mM})$ + dithiothreitol (2 mM); B) NADPH (3 mM) + FAD $(0.1 \mathrm{mM}) ;$ I DHGG; $\|^{2}$ THGG; - Start of TLC.

sors in P e.g. acetate (5), mevalonic acid (16), IPP $(14,17)$, NADPH (18). The reduction is very important in $\alpha T$ synthesis since the prenylating enzyme is specific for $P$ and does not use GG as substrate (6). GG and GGPP synthesis is achieved in a recombinated system of chloroplast envelopes and chloroplast soluble protein from IPP (14). The synthesized GGPP is discharged in the lipid phase of the envelope (14). The enzymes which catalyses the formation of $\alpha T$ in spinach chloroplasts are bound to the envelope $(6,19)$. So it seems very likely that the enzymes which catalyse the reduction are also organized at this membrane. It is not yet clear whether they are bound to the membrane or just get organized at the envelope during time of their activity as those are for the GGPP synthesis. The hydrogenation system seems to be very sensitive to external influences (personal communication of Prof. Dr. R. Douce, (3). We used a very dense chloroplast suspension ( $>3 \mathrm{mg} \mathrm{Chl/ml).} \mathrm{The} \mathrm{dan-}$ ger of desintegration of enzyme systems or dilution of cofactors is much lower. The concentration of endogenous NADPH is high enough to sustain a good conversion rate as can be seen from experiments with FADH (Fig. 1, 2). Regulatory proteins (e.g. thioredoxin) that are known to link light to enzyme activity seem to have only a small effect on the conversion rate. This pro- 
blem has to be studied in more detail, because the synthesis of $\alpha T$ is 1 ight dependent (20) while the reaction from IPP to yield GGPP (14) and from PPP to $\alpha T$ are light independent $(6,19)$.

Chl $a_{G G}$ is synthesized in spinach chloroplasts from IPP by a recombinated system of thylakoid membranes and soluble chloroplast proteins (14). A reduction of $\mathrm{Chl} \mathrm{a}_{\mathrm{GG}}$ in this green systems was not demonstrated, while a stepwise two electron reduction of $\mathrm{Chl} \mathrm{a}_{\mathrm{GG}} \rightarrow \mathrm{Chl} \mathrm{a}_{\mathrm{DHGG}} \rightarrow \mathrm{Chl} \mathrm{a}_{\mathrm{THGG}} \rightarrow \mathrm{Chl}$ a (Chl a ${ }_{\text {DHGG }}$ THGG $=$ Chl a esterified with DHGG, THGG) for etiolated systems is now well established $(1,4,15)$. The chlorophyll synthetase (2) which catalyzes the esterification of chlorophyllide with either GGPP or PPP shows a 2:1 specifity for GGPP in oat seedlings (2). This enzyme is different to chlorophyllase which needs organic solvents to be active. The results presented here demonstrate for the first time that also spinach chloroplasts are able to perform the reduction of $\mathrm{Chl} \mathrm{a}_{\mathrm{GG}}$ to $\mathrm{Chl}$ a. An effect of exogenously supplied NADPH is especially detectable in the increase of Chl a ${ }_{\text {DHGG }}$ and Chl a ${ }_{\text {THGG }}$ while the rate of incorporation in Chl a is constant. Label in Chl a is already detectable after 5 min while $C h l a_{\text {DHGG }}$ and $C h l a_{\text {THGG }}$ accumulate at a later state. These results are in good agreement with a very recent report on the hydrogenation of $\mathrm{Chl} \mathrm{a}_{\mathrm{GG}}$ by etiolated oat seedlings (3). These results indicate that also in fully developed chloroplasts the esterification of chlorophyllide with GGPP and subsequent reduction can take place as well as esterification with PPP. Which alcohol in vivo is esterified with chlorophyllide is not yet clear. A regulatory function of PPP in the chlorophyll synthesis is discussed $(21,22)$ as well as a stimulating effect of GGPP on an endogenous $P$ ( $P P$ ) pool (15). In vivo this regulation might be dependent on the redox status of the chioroplast and it seems possible that both isoprenoid alcohols are esterified to chlorophyllide.

Acknowledgements: We thank Drs. J. Benz and W. Rüdiger for making manuscripts available prior to publication. This work was supported by the Deutsche Forschungsgeme inschaft.

\section{REFERENCES:}

1. Schoch, S., Lempert, U. and Rüdiger, G. (1977) Z. Pflanzenphysiol. 83, $427-436$.

2. Rüdiger, W., Benz, J. and Guthoff, C. (1980) Eur. J. Eiochem. 109, 193 200.

3. Benz, J., Wolf, C. and Rüdiger, W. (1980) Plant Sci. Letters 19, 225-230.

4. Rüdiger, W., Benz, J., Lempert, U. and Steffens, D. (1976) Z. Pflanzenphysiol. $80,131-143$.

5. Costes, C. (1966) Phytochemistry 5, 311 - 324.

6. Soll, J., Kemmerling, M. and Schultz, G. (1980) Arch. Biochem. Biophys. $204,544-550$. 
7. Arbusow, A. and Dumin, A. (1914) Zurnal Russkajo Fiziko-Chimiceskago Obcestva Pri Pretorsgradshom Univertete 46, 295 - 302.

8. Walter. W.M. (1967) J. Label. Compounds 3, 54 - 57.

9. Mayer,H. and Isler, 0. (1971) Methods in Enzymology (Colowick, S.P. and Kaplan, N.O. eds.) 18 c, 491 - 547, Academic Press, New York.

10. Joo, C.N., Park, C.E. and Kates, M. (1973) Can. J. Biochem. 51, 1527 1536.

11. Widmaier, R., Howe, J. and Heinstein, P. (1980) Arch. Biochem. Biophys. $200,609-616$.

12. Jensen, R.G. and Bassham, J.A. (1966) Proc. Nat. Acad. Sci. 56, 1095 1101.

13. Haas, R., Siebertz, H.P., Wrage, K. and Kleine, E. (1980) Planta 148, $238-244$.

14. Block, M.A., Joyard, J. and Douce, R. (1980) Biochim. Biophys. Acta $631,210-219$.

15. Benz, J. (1980) Dissertation, Ludwigs-Maximilians-Universität München.

16. Wellburn, A.R., Stone, K.J. and Hemming, F.W. (1966) Biochem. J. 100, $23 c-25 e$.

17. Skilleter, D.N. and Keckwick, R.G.0. (1970) Phytochem. 9, $153-156$.

18. Wellburn, A.R. (1968) Phytochem. 7, 1523 - 1528.

19. Soll, J., Douce, R. and Schultz, G. (1980) FEBS Letters 112, 293 - 246.

20. Lichtenthaler, H.K. (1973) Ber. Deutsch. Bot. Ges. 86, $313-329$.

21. Gray, J.C. and Kekwick, R.G.0. (1973) Biochem. J. 133, 335 - 347.

22. Liljenberg, C. (1977) Physiol. Plant. 39, 101 - 105. 